\title{
Costs and quality of life for prehabilitation and early rehabilitation after surgery of the lumbar spine Per Rotbøll Nielsen* ${ }^{* 1,2}$, Jakob Andreasen ${ }^{\dagger 3}$, Mikael Asmussen ${ }^{\dagger 4}$ and Hanne Tønnesen ${ }^{\dagger 2}$
}

\author{
Address: ${ }^{1}$ Centre of Head and Orthopaedics, Department of Anaesthesiology, Rigshospitalet, University of Copenhagen, Denmark, ${ }^{2}$ Clinical Unit \\ of Health Promotion/WHO Collaborating Centre for Evidence-Based Health Promotion, Bispebjerg Hospital, University of Copenhagen, \\ Denmark, ${ }^{3}$ Research Unit for Technical Health Assessment, Hvidovre Hospital, University of Copenhagen, Denmark and ${ }^{4}$ Copenhagen Business \\ School, Copenhagen, Denmark \\ Email: Per Rotbøll Nielsen* - rotboell@rh.dk; Jakob Andreasen - ja@mtve.dk; Mikael Asmussen - Mikaelasmussen@post.tele.dk; \\ Hanne Tønnesen - Mikaelasmussen@post.tele.dk \\ * Corresponding author †Equal contributors
}

Published: 9 October 2008

BMC Health Services Research 2008, 8:209 doi:10.1 186/1472-6963-8-209
Received: 18 December 2007

Accepted: 9 October 2008

This article is available from: http://www.biomedcentral.com//472-6963/8/209

(C) 2008 Nielsen et al; licensee BioMed Central Ltd.

This is an Open Access article distributed under the terms of the Creative Commons Attribution License (http://creativecommons.org/licenses/by/2.0), which permits unrestricted use, distribution, and reproduction in any medium, provided the original work is properly cited.

\begin{abstract}
During the recent years improved operation techniques and administrative procedures have been developed for early rehabilitation. At the same time preoperative lifestyle intervention (prehabilitation) has revealed a large potential for additional risk reduction.

The aim was to assess the quality of life and to estimate the cost-effectiveness of standard care versus an integrated programme including prehabilitation and early rehabilitation.
\end{abstract}

Methods: The analyses were based on the results from 60 patients undergoing lumbar fusion for degenerative lumbar disease; 28 patients were randomised to the integrated programme and 32 to the standard care programme.

Data on cost and health related quality of life was collected preoperatively, during hospitalisation and postoperatively. The cost was estimated from multiplication of the resource consumption and price per unit.

Results: Overall there was no difference in health related quality of life scores. The patients from the integrated programme obtained their postoperative milestones sooner, returned to work and soaked less primary care after discharge. The integrated programme was I,625€ (direct costs $494 €$ + indirect costs $I,|3| €)$ less costly per patient compared to the standard care programme.

Conclusion: The integrated programme of prehabilitation and early rehabilitation in spine surgery is more cost-effective compared to standard care programme alone.

\section{Background}

During the recent years improved surgical and anaesthesiological techniques as well as administrative procedures have been developed for fast tracking surgery. This programme describes a multi-modal approach, which includes optimal operation techniques, better pain reduction, early nutrition and aggressive postoperative mobilisation [1]. An important part of the program is to inform and prepare the patients for the accelerated pathway. The results have been promising, especially regarding the eco- 
nomical consequences of the shortened length of stay and rehabilitation[2].

In the same time randomised clinical studies have revealed a large potential for effect of adding preoperative lifestyle intervention (prehabilitation) to conventional surgical procedures. A 6-8 weeks programme of preoperative smoking cessation intervention halved the complication rate after hip- and knee replacement[3], and a 4 weeks programme of preoperative alcohol abstinence intervention halved the development of all kinds of complications in harmful drinkers after colorectal resection[4]. Furthermore, some studies of preoperative physical training showed a beneficial effect on the length of stay and complication rate, while others reported no effect at all $[5,6]$. Hitherto, prehabilitation has not been shown to worsen the postoperative outcome on a randomised trial.

The aim of the present study was to compare the economic impact and quality of life of surgery for degenera- tive lumbar spine disease with and without integration of prehabilitation and early rehabilitation.

\section{Methods}

The present study included data collected in a randomised controlled trial of 60 patients undergoing lumbar fusion for degenerative lumbar disease[7]. After informed consent 28 patients were randomised to an integrated programme and 32 to the standard care programme. Their characteristics are given in table 1 .

Data collection included cost and quality of life for each patient in the preoperative period under hospitalisation and in the postoperative period. The costs originated from three categories; staff resources, equipments and purely bed costs. The bed costs included salary of the nurses and porters, food, clothes, laundry and cleaning.

The preoperative programme for the intervention group involved extra resources for prehabilitation; information and instruction, optimisation of pain treatment[7] in rela-

Table I: Characteristics of the $\mathbf{2 8}$ patients randomised to the integrated programme, which comprehended prehabilitation and early rehabilitation, and the 32 patients randomised to the standard care programme, exclusively

\begin{tabular}{|c|c|c|}
\hline Preoperatively & Integrated programme $n=28$ & Routine programme $n=32$ \\
\hline Women & $17(61 \%)$ & $19(59 \%)$ \\
\hline Age (years) & $48(31-72)$ & $52(31-88)$ \\
\hline Weight (kg) & $77(48-118)$ & $77(5 \mathrm{I}-107)$ \\
\hline BMI $\left(\mathrm{kg} / \mathrm{m}^{2}\right)$ & $25(2 I-33)$ & $26(17-33)$ \\
\hline Daily smokers & $3(11 \%)$ & $5(16 \%)$ \\
\hline Harmful drinkers & 0 & 0 \\
\hline ASA Classification $(I-V)^{a}$ & $\mathrm{I}(\mathrm{I}-\mathrm{II})$ & $\mathrm{I}(\mathrm{I}-\mathrm{II})$ \\
\hline \multicolumn{3}{|l|}{ Postoperatively } \\
\hline Patients with major complications a & 8 & 8 \\
\hline Cardiopulmonary insufficiency & 0 & 0 \\
\hline Thrombo-Embolic complications & 0 & 0 \\
\hline Haematomas & I & 2 \\
\hline Severe pain ( $>70$ at VAS) & 6 & 7 \\
\hline Allergic reaction & I & 0 \\
\hline Patients with minor complications & 4 & 4 \\
\hline Pneumonia (antibiotics) & 0 & 0 \\
\hline Wound infection (antibiotics) & 0 & 1 \\
\hline Urinary tract infection $\left(>10^{5}\right.$ bacteria/ml) & 2 & 0 \\
\hline Urinary retention (tubulation) & 0 & 1 \\
\hline Constipation (laxities) & 2 & 2 \\
\hline Patients with adverse events & 3 & I \\
\hline Delayed order of nursing at home & 2 & 0 \\
\hline Surgery on Friday b & 1 & 1 \\
\hline Second surgery & 0 & I (3\%) \\
\hline Hospital stay after surgery (days) & $5(4-9)^{*}$ & $7(5-15)$ \\
\hline Stay until reaching all milestones & $4(1-6)^{*}$ & $6(3-13)$ \\
\hline Extra stay due to complications & $18^{*}$ & 30 \\
\hline
\end{tabular}

(Numbers and per cent or median and range)

$* \mathrm{P}<0.01$ a Requiring intensive treatment or secondary surgery ${ }^{b}$ Not followed by physiotherapy in the weekend 
tion to the 6-weeks home training programme of $30 \mathrm{~min}$ utes per day followed-up by phone calls and log-books, 6weeks smoking cessation programme with free nicotine replacement therapy and weekly follow-up visits[3], 4weeks alcohol abstinence programme with free medication (benzodiazepines, disulfiram and B-vitamins) and weekly follow-up visits[4]. Postoperatively, the integrated programme included double the time for physiotherapy during their stay at hospital, protein-rich drinks, balanced and patient-controlled epidural analgesia and a follow-up visits for smokers and harmful drinkers. Milestones for both groups are defined as follow: 1 . Assisted positional change in bed, 2. Independent positional change in bed, 3. Assisted moblization to bedside, 4. Independent moblization to bedside, 5. Assisted moblization in walkingframe, 6. Independent moblization to walkingframe, 7. Independent personal hygiene, 8. Independent daily function on ward, 9. Walking without aids, 10. Complete training programme, 11. Independent stair climb and 12. Discharge to home.

For both groups the direct costs were identical for primary surgical intervention and postoperative activities related to the standard care programme.

Postoperatively, data for estimation of the direct costs was collected for each patient regarding length of stay and second surgery, table 1. After discharge, the contact within the first 3 postoperatively months to general practitioners, emergency wards and to physiotherapists was registered. Data collection for indirect costs involved loss of productivity until return to work.

Quality of life was assessed by self-reports. The patients filled in the generic Quality of life survey tool 15D at six different time points (at inclusion, at the day of surgery, at the day of discharge and 1,3 and 6 months postoperatively[8]).

\section{Analyses}

The costs were estimated from multiplication of the resource consumption and unit costs. The focus was on the differences between the two programmes. For that reason, the identical costs for the primary operation and related medication during hospital stay for the two programmes were not included in this analysis.

The loss of productivity was calculated from return to work rates.

\section{Sensitivity analysis}

The calculated cost could be influenced by uncertainty regarding the concrete values for parameters, estimations and associations, because some of the parameters were deterministic point estimates with distribution and variety. This uncertainty has been quantified by a sensitivity analysis in order to identify the robustness of the results cost.

The effects of the two programmes were estimated using the quality of life assessments. Based on the patient reported quality of life measurement, a single index score (15D-score) on a $0-1$ scale, representing the overall health-related quality of life, was calculated for each of the six time points for the two groups respectively by using a set of utility weights. The scores of the two groups were compared using area under curve and Mann-Whitney test. The level of significance was 0.05 .

The analyses were performed using SPSS programme.

\section{Ethical considerations}

The study was performed in accordance with the Helsinki II Declaration, and all patients participated after informed consent. The Regional Scientific Ethical Committee 01041/03 approved the protocol, and the study has been registered in the international protocol registration system http://www.ClinicalTrials.gov, ID NCT 00459966.

\section{Results}

The integrated programme was 494 less costly than the standard care programme regarding direct costs. The direct costs per patient were higher in the preoperative period due to the prehabilitation programme, but lower in the postoperative period due to shorter length of stay, see table 2 .

There was a non-significant trend that the patients randomised to the integrated programme returned faster to work, 77 days (14-90), compared to the patients randomised to the standard care programme, 88 days (54$90) ; p=0,092$. The indirect costs as reported by the loss of productivity was correspondingly lower for the integrated programme; 8,021 versus 9,152, when estimated by multiplication of the number of days and the Danish average salary (104 per day).

The accumulated estimate of the differences in direct and indirect costs was 1,625 (494+1,131) in favour of the integrated programme.

Regarding health related quality of life, there were no differences between the two groups when comparing the 15D-scores (table 3).

The analysis of sensitivity included the best cases and worst cases for time consumption, salary, bed-cost, length of stay and return to work rate. 
Table 2: Pre- and postoperative differences in direct costs per patient randomised to the integrated programme, which included prehabilitation and early rehabilitation, and to the standard care program (in Euros)

\begin{tabular}{|c|c|c|c|c|}
\hline & \multicolumn{2}{|c|}{ Integrated programme } & \multicolumn{2}{|c|}{ Standard care programme } \\
\hline & In total & Per patient & In total & Per patient \\
\hline $\begin{array}{l}\text { Preoperative introduction } \\
\text { I) Physiotherapist: I } \mathrm{h} \times 28 \text { patients } \times 27 €^{*}=\mathbf{7 5 6} € \\
\text { I) Physician support: } 0.16 \mathrm{~h} \times 5 \text { patients } \times 34 \epsilon^{*}=\mathbf{2 7} € \\
\text { R) Nurse: } 0.25 \mathrm{~h} \times 32 \text { patients } \times 28 \epsilon^{*}=\mathbf{2 2 4 €}\end{array}$ & 783 & 28 & 224 & 8 \\
\hline
\end{tabular}

\begin{tabular}{|c|c|c|c|c|}
\hline $\begin{array}{l}\text { Training } \\
\text { I) Physiotherapist: } \mathrm{I} / 2 \mathrm{~h} \times 28 \text { patients } \times 27 € * \times 2 \text { times }=\mathbf{2 7} €\end{array}$ & 756 & 27 & 0 & 0 \\
\hline $\begin{array}{l}\text { Smoking intervention } \\
\text { I) Nurse: } 2.8 \mathrm{~h} \times 3 \text { smokers } \times 28 € *=235 € \\
\text { i) Equipments/medication: } 65 € \times 3 \text { patients }=195 €\end{array}$ & 430 & 15 & 0 & 0 \\
\hline
\end{tabular}

Alcohol intervention
I) Nurse: $2.8 \mathrm{~h} \times 0$ smokers $\times 28 €^{*}=0 €$
I) Equipments/medication: $27 € \times 0$ patients $=0 €$

I) Equipments/medication: $27 € \times 0$ patients $=0 €$

\begin{tabular}{|c|c|c|c|c|}
\hline $\begin{array}{l}\text { Optimised pain treatment } \\
\text { I) Physician: } 0.25 \mathrm{~h} \times 28 \text { patients } \times 34 €^{*}=\mathbf{2 3 8 €}\end{array}$ & 238 & 9 & 0 & 0 \\
\hline Preoperative costs & & 79 & & 8 \\
\hline $\begin{array}{l}\text { Postoperative hospital training } \\
\text { I) Physiotherapist: I } \mathrm{h} \times 28 \text { patients } \times 5 \text { times } \times 27 €^{*}=\mathbf{3 , 8 8 0 €} \\
\text { R) Physiotherapist: } \mathrm{I} / 2 \mathrm{~h} \times 32 \text { patients } \times 7 \text { times } \times 27 \epsilon^{*}=\mathbf{3}, \mathbf{0 2 4} €\end{array}$ & 3,880 & 135 & 3,024 & 95 \\
\hline $\begin{array}{l}\text { Pain treatment } \\
\text { I) Senior nurse: } 0.16 \mathrm{~h} \times 3 \text { times } \times 28 \text { patients } \times 30 * €=\mathbf{4 0 3} € \\
\text { I) Specialist: } 0.16 \mathrm{~h} \times 3 \text { times } \times 28 \text { patients } \times 6 \mathrm{I} €^{*}=\mathbf{8 2 0} € \\
\text { R) Senior nurse: } 0.16 \mathrm{~h} \times 3 \text { times } \times 32 \text { patients } \times 30^{*} €=\mathbf{4 6 0} € \\
\text { R) Specialist: } 0.08 \mathrm{~h} \times 3 \text { times } \times 32 \text { patients } \times 6 \mathrm{I} €^{*}=\mathbf{4 6 8} €\end{array}$ & $\mathrm{I}, 223$ & 44 & 928 & 29 \\
\hline
\end{tabular}

Hospital stay
I) Bed-price: $164 €$ per day $\times 5$ days $\times 28$ patients $=\mathbf{2 2 , 9 6 0 €}$
R) Bed-price: $164 €$ per day $\times 7$ days $\times 32$ patients $=\mathbf{3 6 , 7 3 6 €}$

\begin{tabular}{llll}
\hline Second surgery & 0 & 0 & 258 \\
R) Stop bleeding: $\mathbf{8 , 2 4 7 €}$ & & 0
\end{tabular}

\begin{tabular}{|c|c|c|c|c|}
\hline Postoperative hospital costs per patient & & 999 & & $\mathbf{1 , 5 3 0}$ \\
\hline $\begin{array}{l}\text { Postoperative primary care GP } \\
\text { I) Contact: } 43 \text { contacts } \times \mid 4 € \text { per contact }=\mathbf{6 2 3} € \\
\text { R) Contact: } 6 \mid \text { contacts } \times \mid 4 € \text { per contact }=\mathbf{8 5 4 €}\end{array}$ & 623 & 22 & 854 & 27 \\
\hline $\begin{array}{l}\text { Emergency contacts } \\
\text { I) Contact: } 3 \text { contacts } \times 24 € \text { per contact }=\mathbf{7 2 €} \\
\text { R) Contact: } 10 \text { contacts } \times 24 € \text { per contact }=\mathbf{2 4 0 €}\end{array}$ & 72 & 2 & 240 & 8 \\
\hline $\begin{array}{l}\text { Physiotherapy } \\
\text { I) Private physiotherapist: } 20 \mathrm{~h} \times 45 €^{*}=900 € \\
\text { R) Private physiotherapist: } 67 \mathrm{~h} \times 45 €^{*}=3,0 \mathrm{I} € €\end{array}$ & 900 & 32 & 3,015 & 94 \\
\hline $\begin{array}{l}\text { Medical treatment } \\
\text { I) Medical treatment: I I } 20 € \\
\text { R) Medical treatment: } 32 €\end{array}$ & 1,120 & 40 & 32 & $\mathrm{I}$ \\
\hline Postoperative primary care costs per patients & & 96 & & 130 \\
\hline Balance for direct costs per patient & & 1,174 & & 1,668 \\
\hline
\end{tabular}

* Salary per hour 
This analysis of the extreme values showed a variation in direct cost from 657 to 3,239 for the standard care programme and 553 to 2532 for integrated programme. The variation in total costs were 10,148 to 15,906 of the standard care programme and 8,117 to 11,884 for the integrated programme.

This analysis of the extreme values did not change the conclusion of the main base analysis, table 4 .

\section{Discussion}

This study showed that prehabilitation supplemental to early rehabilitation after surgery of the lumbar spine is cost effective regarding direct hospital costs as well as indirect costs. The prehabilitation programme made the patient reach the postoperative milestones sooner, thus reducing the period of "inability" and thereby the length of stay significantly. The prehabilitation programme was not followed by more complications or pain.

This is the first time to evaluate the combination of prehabilitation and early rehabilitation after surgery of the lumbar spine. Previous studies of cost effectiveness of spine surgery had focused upon the surgical technique[9] or compared surgical intervention with non-surgical intervention[10].

The main effect of integrated programmes after surgery alone is a shorter hospitalization and reconvalescence based on better surgical and anaesthesiological techniques as well as patient-doctor agreements of faster rehabilitation. When comparing our length of stay to other studies, it is important to pay attention to possible difference regarding inclusion or exclusion of rehabilitation in the surgical department.

In the standard care programme the one case of revision surgery added costs of 258 /patient. As seen in table 2 this complication account for $15 \%$ of the extra costs in the standard care group. The complication may not be representative for the group and could be an occasional result. However, this patient had increased risk for complications due to smoking, which would have been preventable by the comprehensive prehabilitation programme. Even without this complication the costs of the standard care group would still be higher compared to the intervention group.

Integrated programmes have been shown to be cost effective for other surgical interventions than spine surgery; resection of colon[11], aorta surgery[12], lung resection[13], and orthopaedic surgery $[14,15]$

The prehabilitation programme did not change the complication rate and could therefore be interpreted as a waste of time and money. However, it did allow for an earlier return to work and decreased the amount of medical required post-operatively and the programme is therefore worthwhile given the economic benefits documented.

Evaluation of prehabilitation programmes of smoking cessation or alcohol intervention in standard surgical programmes showed a significant reduction in development of postoperative complications that required treatment $[3,4]$. Physical training programmes before hip- or knee replacement have shown contra-dictionary results which may however, be due to differences in intensity, duration and comprehensiveness of the evaluated training programmes $[6,16]$.

When generalising the results of the present study the limitations should be considered. Our study is not generalisable owing to the country-specific differences in costs and policy. The difference of LOS in US an in Denmark is probably due to different routines regarding postoperative rehabilitation. The LOS in our study included rehabilitation at the surgical department. All patients was discharged directly to their home, nobody was transferred for

Table 3: Health related quality of life I5D-scores[8] for the patients randomised to the integrated program and the patients randomised to the standard care program

\begin{tabular}{lcc}
\hline 8 weeks preoperatively & $\begin{array}{c}\text { Integrated programme } \\
0.83(0.67-1.00)\end{array}$ & $\begin{array}{c}\text { Routine programme } \\
0.79(0.63-0.95)\end{array}$ \\
\hline Operation day & $0.85(0.74-0.99)$ & $0.82(0.65-.096)$ \\
\hline Day of Discharge & $0.83(0.62-1.00)$ & $0.79(0.48-0.94)$ \\
\hline I month postoperatively & $0.88(0.74-0.99)$ & $0.86(0.66-0.96)$ \\
\hline 3 months postoperatively & $0.90(0.73-1.00)$ & $0.89(0.62-1.00)$ \\
\hline 6 months postoperatively & $0.91(0.73-1.00)$ & $0.90(0.69-1.00)$ \\
\hline
\end{tabular}

(Median and range) 
Table 4: The variety of the pre- and postoperative costs in the two programmes reflected by the most optimistic and most pessimistic estimates (Euros)

\begin{tabular}{lcccccc}
\hline & \multicolumn{3}{c}{ Integrated programme } & \multicolumn{2}{c}{ Routine programme } \\
\cline { 2 - 7 } & Most optimistic & Base case & Most pessimistic & Most optimistic & Base case & Most pessimistic \\
\hline Preoperative costs & 22 & 79 & 88 & 5 & 9 & 1,530 \\
\hline Postoperative hospital costs & 449 & 999 & 2,334 & 536 & 13,074 \\
\hline Postoperative primary care costs & 82 & 96 & 111 & 116 & 130 & 1,668 \\
\hline Direct costs & 553 & 1,174 & 2,532 & 657 & 3,239 \\
\hline Indirect costs & 7,011 & 8,021 & 9,098 & 8,834 & 9,152 & 9,427 \\
\hline Balance & 8,117 & 10,369 & 11,884 & 10,148 & 12,488 & 15,906 \\
\hline
\end{tabular}

or needed further physical therapy. The LOS of our control group corresponded to the LOS of recent studies, e.g. Elder JB and co-authors from Los Angeles, CA[17]. Their control and intervention groups stayed 6.96 vs. 6.36 days, respectively. Our LOS was 7 vs. 5 days. Another measurement could be physical therapy clearance for discharge 6.40 vs. 5.92 days reaching all milestones in our study; 6 vs. 4 days. A study of minimal invasive surgery presented a very short stay 3 and 4 days, but it did not include information on rehabilitation during the stay or after discharge from the surgical department[18].

The number of 60 patients was too small for detailed evaluation regarding types of complications, minor differences in quality of life and costs, which may all, have been overlooked due to a type-2 failure. Furthermore, the quality of life was assessed using the generic questionnaire $15 \mathrm{D}[8]$, which is reliable for comparison the life quality for patients suffering from different illnesses. It may, however, not be sensitive enough to identify differences between the two randomised groups.

A high compliance in the intervention group is essential for a proper evaluation of a beneficial effect on the outcome. In the present study the patients in the prehabilitation group were compliant to more than $80 \%$ of the training passes.

The estimations may be vitiated by different degrees of error regarding assessments, assumptions and associations. This is partly due to the use of deterministic pointestimates that are characterised by having no distribution or variety. The possible error seems limited in the present study, since the analysis of sensitivity based on both the most pessimistic and optimistic estimates did not change the conclusion, that a integrated programme of prehabili- tation and early rehabilitation in spine surgery is more cost-effective than standard care, exclusively.

\section{Conclusion}

This is the first study in this specific area of integrating prehabilitation and early rehabilitation after surgery of the lumbar spine and there is an inborn risk of type- 1 failure, which can only be reduced by repeating the study. To overcome the potential type- 2 failures the future studies should collect a sizeable number of data for the more detailed evaluation, and use a more specific questionnaire for assessment of quality of life in patients undergoing spine surgery.

\section{Competing interests}

The authors declare that they have no competing interests.

\section{Authors' contributions}

PRN designed and managed the study, recruited the patients and obtained, recorded, analyzed and interpreted the data. JA and MA analysed and interpreted the data. HT designed the study and analysed and interpreted the data. PRN and HT drafted the manuscript. JA and MA revised the manuscript critically. All authors read and approve the final manuscript.

\section{Acknowledgements}

Project Coordinator Rie Raffing WHO-CC is acknowledged for technical assistance. Danish National Board of Health supported the study by a grant from their Unit for Health Technology Assessment.

\section{References}

I. Kehlet H, Wilmore DW: Fast-track surgery. $\mathrm{Br} J$ Surg 2005, 92:3-4.

2. Folkersen J, Andreasen J, Basse L, Jakobsen $\mathrm{DH}$, Kehlet $\mathrm{H}$ : Health technology assessment of fast tracking colorectal surgery. English summary I 2005 [http://www.sst.dk/publ/Publ/2005/CEMT/ acc kolonkirurgi/fast track surgery Summary.pdf]. Copenhagen, Danish National Board of Health Ref Type: Report 
3. Moller AM, Villebro N, Pedersen T, Tonnesen H: Effect of preoperative smoking intervention on postoperative complications: a randomised clinical trial. Lancet 2002, 359: I I4- I I7.

4. Tonnesen H, Rosenberg J, Nielsen HJ, Rasmussen V, Hauge C, Pedersen IK, Kehlet H: Effect of preoperative abstinence on poor postoperative outcome in alcohol misusers: randomised controlled trial. BM] |999, 3 | 8:|3||-|3|6.

5. Gocen Z, Sen A, Unver B, Karatosun V, Gunal I: The effect of preoperative physiotherapy and education on the outcome of total hip replacement: a prospective randomized controlled trial. Clin Rehabil 2004, 18:353-358.

6. Rooks DS, Huang J, Bierbaum BE, Bolus SA, Rubano J, Connolly CE, Alpert S, Iversen MD, Katz JN: Effect of preoperative exercise on measures of functional status in men and women undergoing total hip and knee arthroplasty. Arthritis Rheum 2006, 55:700-708.

7. Nielsen PR, Dahl B, Tønnesen H: Prehabilitation and Fast-track surgery: Randomized Clinical Trail with spinal surgery. Spine, Editorial Board 2007.

8. Sintonen $\mathrm{H}$ : The I5D instrument of health-related quality of life: properties and applications. Ann Med 200I, 33:328-336.

9. Soegaard R, Christensen FB, Christiansen T, Bunger C: Costs and effects in lumbar spinal fusion. A follow-up study in 136 consecutive patients with chronic low back pain. Eur Spine J 2006.

10. Gibson JNA, Waddell G: Surgery for degenerative lumbar spondylosis: Updated Cochrane review. Spine 2005, 30(20):2312-2320.

II. Basse L, Raskov HH, Hjort JD, Sonne E, Billesbolle P, Hendel HW, Rosenberg J, Kehlet $\mathrm{H}$ : Accelerated postoperative recovery programme after colonic resection improves physical performance, pulmonary function and body composition. $\mathrm{Br} J$ Surg 2002, 89:446-453.

12. Podore PC, Throop EB: Infrarenal aortic surgery with a 3-day hospital stay: A report on success with a clinical pathway. I Vasc Surg 1999, 29:787-792.

13. Tovar EA, Roethe RA, Weissig MD, Lloyd RE, Patel GR: One-day admission for lung lobectomy: an incidental result of a clinical pathway. Ann Thorac Surg 1998, 65:803-806.

14. Healy WL, Ayers ME, lorio R, Patch DA, Appleby D, Pfeifer BA: Impact of a clinical pathway and implant standardization on total hip arthroplasty: a clinical and economic study of shortterm patient outcome. J Arthroplasty 1998, 13:266-276.

15. Scranton PE Jr: The cost effectiveness of streamlined care pathways and product standardization in total knee arthroplasty. I Arthroplasty 1999, 14:182-186.

16. Gocen Z, Sen A, Unver B, Karatosun V, Gunal I: The effect of preoperative physiotherapy and education on the outcome of total hip replacement: a prospective randomized controlled trial. Clin Rehabil 2004, 1 8:353-358.

17. Elder JB, Hoh DJ, Wang MY: Postoperative continuous paravertebral anesthetic infusion for pain control in lumbar spinal fusion surgery. Spine 2008, 33:210-218.

18. Wang JC, Haid RW Jr, Miller JS, Robinson JC: Comparison of CD HORIZON SPIRE spinous process plate stabilization and pedicle screw fixation after anterior lumbar interbody fusion. Invited submission from the Joint Section Meeting On Disorders of the Spine and Peripheral Nerves, March 2005. J Neurosurg Spine 2006, 4:132-136.

\section{Pre-publication history}

The pre-publication history for this paper can be accessed here:

http://www.biomedcentral.com/1472-6963/8/209/pre pub
Publish with Biomed Central and every scientist can read your work free of charge

"BioMed Central will be the most significant development for disseminating the results of biomedical research in our lifetime. "

Sir Paul Nurse, Cancer Research UK

Your research papers will be:

- available free of charge to the entire biomedical community

- peer reviewed and published immediately upon acceptance

- cited in PubMed and archived on PubMed Central

- yours - you keep the copyright
BioMedcentral 